\title{
Sciences of the Ocean, Physical and Otherwise'
}

\author{
Warren S. Wooster \\ University of Washington · Seattle Washington USA
}

\begin{abstract}
Study of the world ocean requires not only interaction among scientific disciplines but also cooperation among countries. Scientists have played an important role in deciding how this international cooperation should be organized and conducted. From its origin eighty years ago under the leadership of Prince Albert of Monaco, the International Association for the Physical Sciences of the Oceans (IAPSO) has been at the center of this effort among scientists to create organizations that would serve their purposes. IAPSO discussions have dealt not only with the principal scientific questions of their time but also with building the international infrastructure within which the research could be developed.

An early question was whether marine scientists should be concerned only with pure science or should their organizations also consider the applications of that science. Thought was given how best to ensure the timely exchange of information on scientists and institutions engaged in ocean research, on improvement of the methods scientists were using, on their plans for research cruises, and on publication of their findings. Cruises sometimes included both physicists and biologists, and it was evident that these specialists were often working on different aspects of the same problems. The nature of this cooperation was reflected in the non-governmental organizations such as IAPSO and those such as the International Association for Biological Oceanography $(I A B O)$ that later arose within the International Council of Scientific Unions (ICSU). These became somewhat linked through their participation in the governance of the Scientific Committee on Oceanic Research (SCOR).

In the intergovernmental world, the Intergovernmental Oceanographic Commission (IOC) joined the more specialized agencies dealing with subjects like fisheries and meteorology. In recent years, spurred largely by realization of the potential impacts of climate change, large interdisciplinary and international programs, such as Global Ecosystem Dynamics (GLOBEC), Joint Global Ocean Flux Studies (JGOFS), and Global Ocean Observing System (GOOS) have been developed through joint action of scientific and governmental institutions. IAPSO has steered a steady course through these turbulent developments as it pursues its principal focus on promoting and promulgating the findings of marine scientific research.
\end{abstract}

When asked to talk at this session about the early days of IAPSO, I expressed considerable reluctance. Those days were before my time, I was less acquainted with IAPSO than with several other international organizations, and I had already learned from professional historians that amateurs like me were only good for anecdotes, not for serious analysis. I prepared my excuses carefully and responded with a firm and negative position. My presence at this meeting is evidence of how persuasive my argument was!

I set out to read the reports of the organization, the Comptes Rendus and later the Proceedings, in order to identify its initial personality and to see how that has influenced its later behavior. The early reports were all in French, a challenge to read although from my United Nations Educational, Scientific and Cultural
Organization (UNESCO) years in Paris I recognized a certain formalism characteristic of such reports. An initial discovery was that these days were not so much before my time after all. The Section of Physical Oceanography, created along with the International Union of Geodesy and Geophysics (IUGG) in July 1919 and with Prince Albert of Monaco as its President, first met in January 1921, a few weeks before I was born!

Whereas Walter Munk will talk about the evolution of physical oceanography (this issue of Oceanography), I intend to discuss the development of international cooperation in oceanography, and especially as it has transpired during the long existence of this section now known as the International Association for the Physical Sciences of the Oceans. Thus my reading focused on reports of the business sessions, resolutions, and presi- 


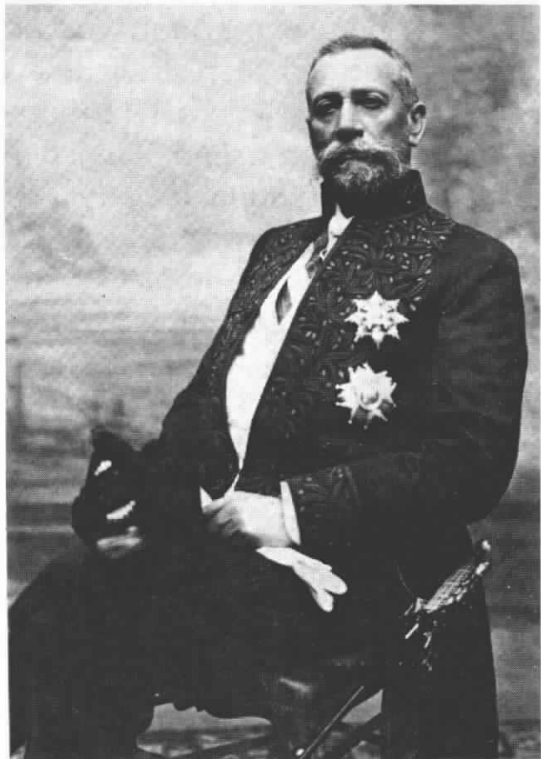

Albert I of Monaco

Although the first IAPO participants were mostly European, they did realize that the world ocean extended beyond the Mediterranean and North Atlantic, and so decided to establish special sub-commissions for each of the major ocean basins-Atlantic, northern European Seas, Mediterranean, Pacific, and Indian Ocean. In a prophetic move, they designated two existing regional organizations, the International Council for the Exploration of the Sea, ICES, and the International Council for the Scientific Exploration of the Mediterranean, ICSEM, as the sub-commissions for their regions. The interleaving of international organizations and players therein came to characterize the development of these organizations.

A few years later, at its meeting in Madrid, the Section considered an ICES proposal to organize a grand campaign to study the world ocean in the footsteps of the Challenger Expedition. This was apparently inspired by a failed attempt to acquire the Prince's vessel Hirondelle before it was sold to the Americans. Thoughts were given to construction of a proper vessel for large scale exploration, but it would probably be too expensive (1.5 million Danish crowns), and other approaches should be considered. While committing no funds, ICES would be prepared to undertake general direction of the work since "the Council was then the only international marine research organization in existence" (Went, 1972, p. 63).

In the course of these discussions, it was agreed to undertake with ICES the study of a possible international organization for marine research. In 1929, the pending revision of IUGG statutes was important to the Section because it felt the need to work with biology, then organized within a different Union (International Union of Biological Sciences, IUBS). Prince Albert had envisioned a separate Union for oceanography with two grand sections, for physical and for biological oceanography. The IAPSO Executive Committee, considering it impossible to study one aspect without being concerned in large measure with the other, supported the view that there should be a special union, and so recommended to the parent body, IUGG.

Yet another model arose during the 1930 General Assembly in Stockholm. President De Buen proposed that the section should become a true Federation of Oceanographic Institutes in the various countries and should be recognized as such by governments. The proposal was opposed by Professor Proudman who considered that the admission of biologists would create all sorts of difficulties. The Section did agree that it should be renamed the International Association of Physical Oceanography, IAPO, and as such could develop its own statutes and hold its General Assemblies where and when it chose. At its first General Assembly (1933 
in Lisbon), the new statutes made clear that the Association would be concerned with those parts of oceanography that utilize mathematics, physics, and chemistry in the scientific study of the sea.

The following Assembly (1936 in Edinburgh) agreed on who could be considered IAPSO Membersi.e., countries that adhere to the Union and, as guest members, international organizations concerned with physical oceanography (such as ICES, ICSEM, and the International Hydrographic Bureau). This reference to "countries" as members continues even in the latest version (1979) of the statutes available to me. In this confusing usage, the term apparently refers not to governments, the usual meaning, but to national academies of science and equivalent bodies. The distinction becomes important when inclusion of a scientific community not identified with a widely recognized country, e.g., the Academia Sinica of Taipei, is under consideration.

In September 1939, the last General Assembly before World War II took place in Washington D.C. Nine years would elapse before the Association would meet again, in Oslo in 1948, but it would take real detective work to find any evidence of the hostilities in the records of either meeting. The Oslo assembly was noteworthy in that it was presided over by Harald Sverdrup, my first teacher in oceanography (and probably Professor Munk's). In his Presidential address, he said:

"On an earlier occasion, I have pointed out (Sverdrup, H.U., 1947: New international aspects of oceanography. Proc.Am.Phil.Soc., 91, 75-78) that it may become necessary to establish an independent technical organization which in particular will have to deal with matters of international co-operation of interest to government agencies concerned with oceanography. One may visualize a development comparable to that which has taken place in meteorology, where technical and scientific international bodies exist with overlapping membership. In our field we may experience still another development. On the initiative of the Union of Biological Sciences there has been created an International Mixed Commission on Oceanography with representatives of various branches of marine biology as well as of physicalchemical oceanography. The establishment of this commission expresses the need for international cooperation within the broad fields of all marine sciences and out of this commission there may grow an International Union of Oceanography. If this happens, we can expect that many of our members will also join such a Union, but otherwise the developments should not alter the status of our Association. We shall always need it in order to remain in contact with the other geophysical sciences and in order to present and discuss our special scientific problems."

This joint commission of IUGG and IUBS was a first formal step towards a more interdisciplinary organization of marine science. A few years later, however, after having decided to restrict its activities to investigations of the deep sea floor, it proposed creation of the journal Deep-Sea Research and planned for its work to be continued by another suitable body after 1957 .

At the Seventh General Assembly, in Toronto that year, it was reported that the Joint Commission had been abolished by ICSU and replaced by a Special Committee on Oceanic Research (SCOR). Meanwhile UNESCO, after discussions with representatives of IAPSO and other bodies, decided to establish an International Advisory Committee on Marine Sciences (IACOMS). This flurry of organizational activity led to a discussion of the relation among them. Each had somewhat different objectives-IACOMS the development of various kinds of marine science activities in countries where these do not exist, and SCOR the promotion of aspects of marine sciences where two or more Unions are concerned. With the hope that effective communication would prevent overlap, IAPO welcomed the formation of these new organizations and endorsed the proposal for what became the International Oceanographic Congress organized by the American Association for the Advancement of Science (AAAS) and held in New York at the United Nations headquarters in the fall of 1959.

Now there ensues a curious gap in the record. Proceedings of the next IAPO meetings, July 1960 in Helsinki and August 1963 in Berkeley, have never been published. There is, however, a relevant report on the 1960 meeting from J.N. Carruthers to the British National Committee:

The problem of getting a quart in a pint pot is nothing new for IAPO, but now that the quart seems to have grown well towards gallon size, things are becoming serious. The business side has itself become burdensome, and some people wonder whether the great umbrella body now in prospect (the IOC) might not one day take over all business so that the professional associations can occupy themselves only with science.

The "great umbrella", the Intergovernmental Oceanographic Commission, was then being manufactured and came into operation the following year. IOC is a global intergovernmental organization whose stated purpose, to further investigation of the ocean and its resources, is indistinguishable from those of the regional intergovernmental organization, ICES, and the non-governmental scientific organization, SCOR. But with regard to Carruthers' point, one must note that the business and approach of governments and of scientists are likely to differ widely in many instances.

At the 1967 IUGG General Assembly in Switzerland, the association acquired its present name, the International Association for the Physical Sciences of the Ocean (IAPSO), reemphasizing the predominantly physical nature of its interests. IAPSO Secretary, Ilmo Hela reported that the committee considering the 


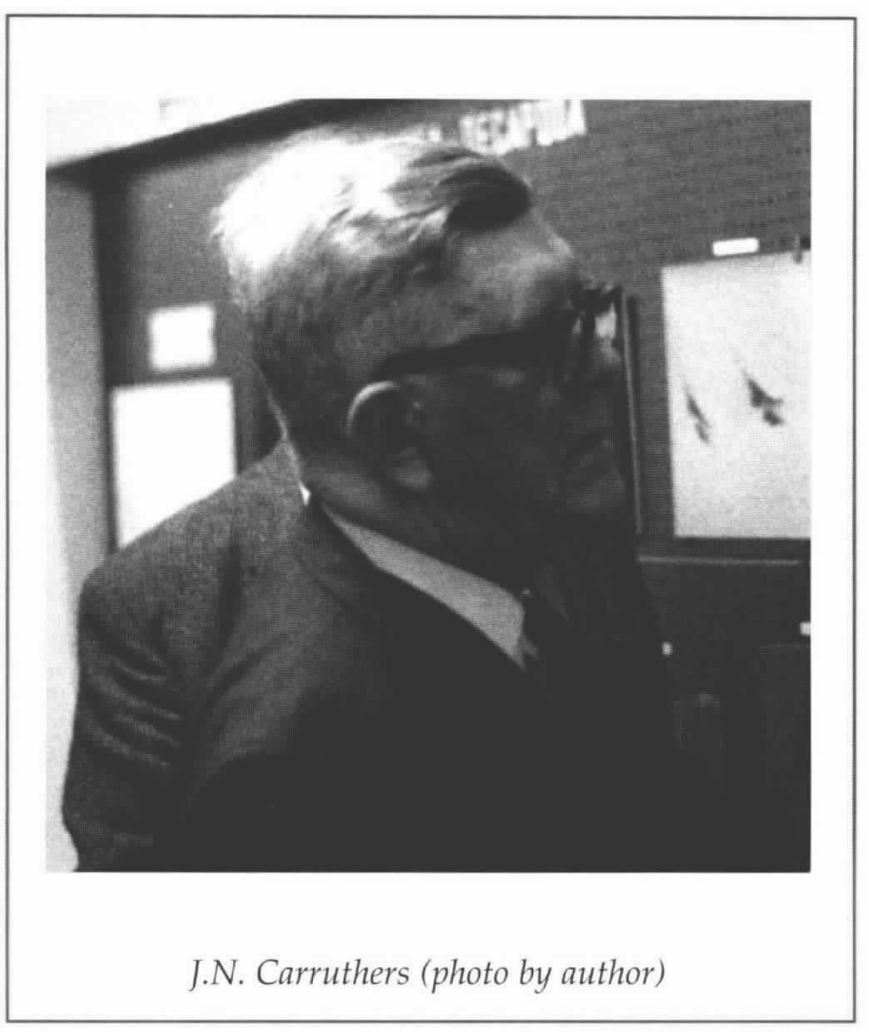

future structure of IUGG proposed that the Associations should act as advisors to intergovernmental bodies. But with SCOR already an official advisor to IOC, should ICSU be asked to consider giving IAPSO a similar role? The committee observed that intergovernmental bodies with more than one advisor tend to play one off against the other. As Hela comments "This enables the officers of the intergovernmental agencies to ignore all the advice they receive and to do instead what some fonctionnaire wanted to do all along."

The question of IAPSO vs SCOR as adviser to IOC had actually been resolved by the General Assembly of ICSU in Bombay in early 1966 when a revision of the SCOR constitution enlarged its Executive Committee to include the presidents of IAPSO and the analogous biological and geological organizations, IABO and CMG. This provided these associations with a real voice and continuing relationship with the interdisciplinary SCOR and thereby a significant role in its advisory relationship with IOC.

In his 1967 presidential address, Roger Revelle spoke of the IOC as having made a good start since its opening in 1961, but suffering from lack of its own budget. It might be better, he thought, that there be an Intergovernmental World Oceanographic Organization [IWOO], with a separate budget and with broad responsibilities for ocean forecasting, development of marine resources, and stimulation of marine science. It would need a counterpart controlled by scientists, and this could be the future of a broader IAPSO, in the long run as part of an International

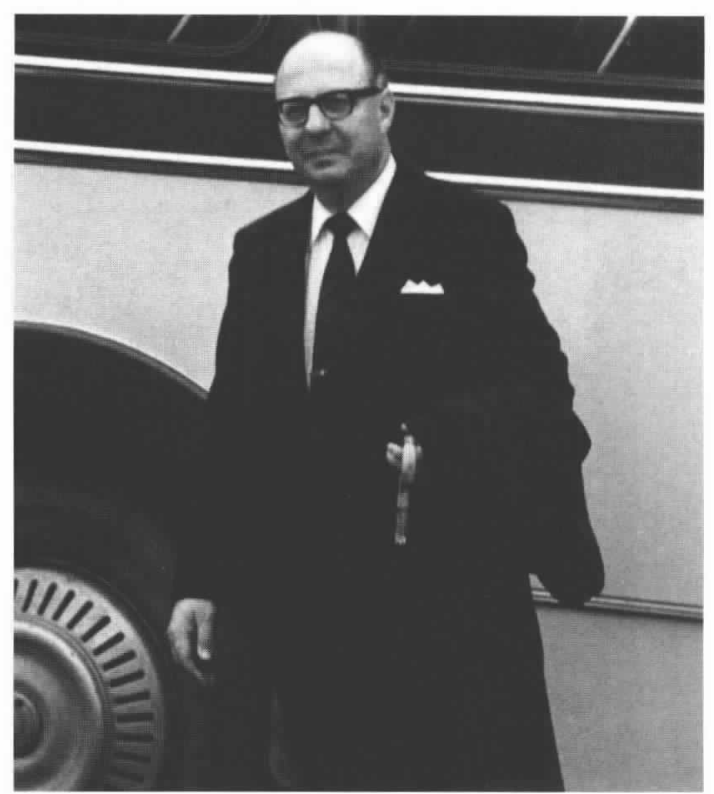

Ilmo Hela (photo by author)
Union of Marine Sciences (IUMS). The functions of the new Union would include to help communication among scientists, to develop infrastructure (standards, nomenclature, bibliographies, information exchange, methods intercalibration) and "to exert an influence for scientific integrity and imaginative change" in the proposed intergovernmental organization.

Revelle's remarks about IWOO presumably reflected the views of a Joint Working Group of the several advisory bodies to IOC that had met in July 1967. Its recommendation for long-term action was

"that the member governments of the United

Nations family and the various United Nations agencies give early and thorough consideration to the advisability and feasibility of establishing a central intergovernmental oceanic organization to deal with all aspects of ocean investigations and the uses of the sea."

Subsequently, the Association asked its Executive Committee, together with other relevant international organizations, to study the desirability and feasibility of establishing an IUMS dealing with all aspects of ocean sciences (including marine biology). The next IAPSO General Assembly should, if possible, be convened jointly with $\mathrm{SCOR}, \mathrm{IABO}$, the Commission on Marine Geology, CMG (of the International Union of Geological Sciences, IUGS) and the International Association for Meteorology and Atmospheric Physics (IAMAP). Following this recommendation, IAPSO held its $15^{\text {th }}$ General Assembly in Tokyo, September 1970, with other organizations during the Joint Oceanographic Assembly. 


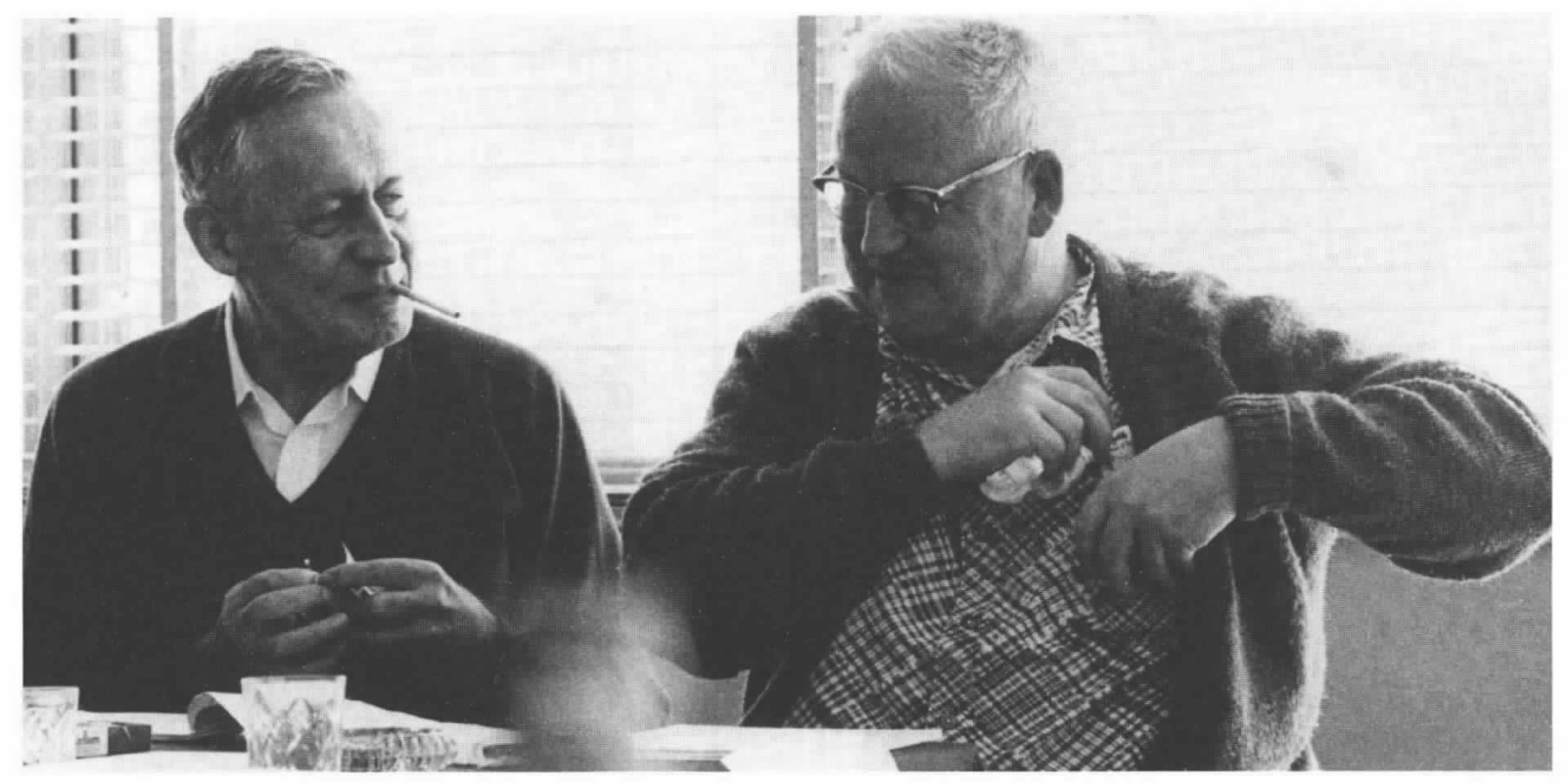

Roger Revelle (left) and Wib Chapman (photo by author)

All previous IAPSO meetings had been in Europe or North America, and this was the first held outside of an IUGG General Assembly. At one session, the proposed International Union of Marine Sciences was discussed, reflecting the growing awareness of the importance of interdisciplinary problems and the need for interdisciplinary action to be abetted rather than inhibited by the institutional structure of the field. A poll of National Correspondents of IAPSO showed that 13 favored creation of IUMS with three opposed. Ultimately, however, the arrangement of a strengthened SCOR was favored with the various associations remaining affiliated with their parent Unions while participating in the expanded and strengthened SCOR

Dietrich, in his 1970 Tokyo Presidential Address referred to Revelle's 1967 address, Unity and fission in oceanography.

"He did it in his ingenious manner by summarizing the centrifugal and centripetal tendencies in our science. On one side we are confronted with the centrifugal tendencies, namely with the explosive growth of interest in the ocean, thereby demanding a great deal of marine scientists than ever before. That means rapid growth of specialization and along with it an increased number of oceanographers, coupled with an increasing development of local interests, and of local applications. On the other side, there are centripetal tendencies. Marine scientists are brought together in the growing institutions, and closely linked by both the indivisibility of the ocean and its extraterritorial nature, because the ocean does not belong to any man or any nation. The consequences of these centripetal tendencies are the appropriate scientific organizations which have to adjust their activities to the fast development in our science."

These issues have continued to reverberate in subsequent IAPSO meetings. For example, George Deacon, who had served as President from 1960 to 1963, was named by President Lacombe in 1975 to chair a "Group of Wise Men" to review and evaluate present IAPSO structure, to consider ways to improve IAPSO action with respect to other organizations and to increase IAPSO impact on the progress of oceanography. While that group met and proposed ways to enhance coordination within IAPSO, it did not propose new ways to deal with inter-organization relations.

I am interested, as has been IAPSO, in these questions of interactions between physical and biological scientists of the ocean, of institutional arrangements that affect such interactions, and of interactions between scientific and governmental organizations. 


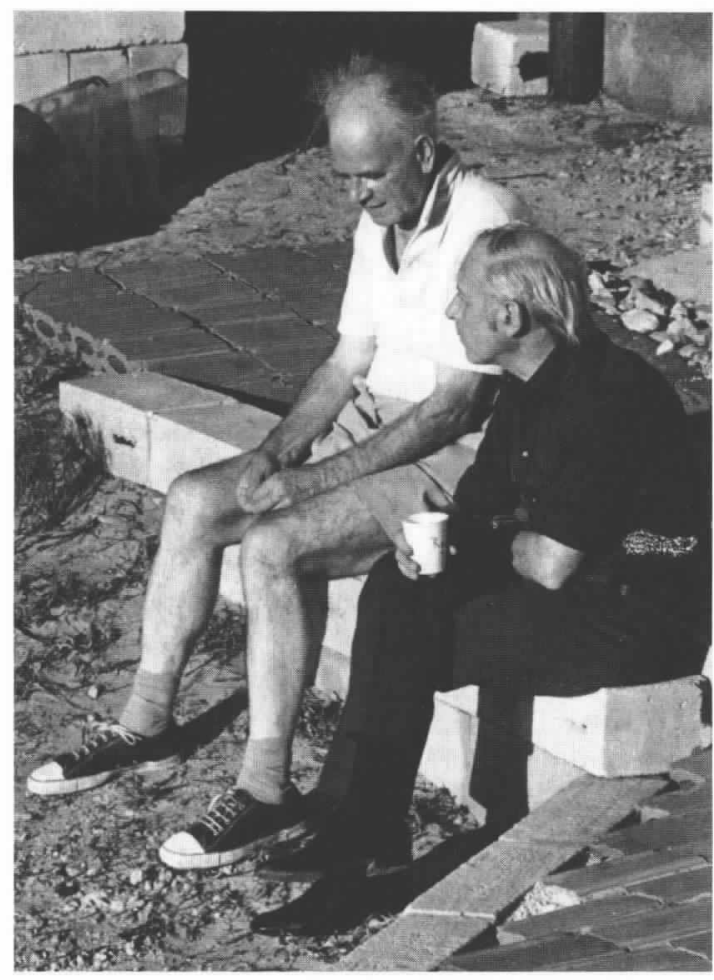

G.E.R. Deacon (left) and Ron Currie (photo by author)

Additional light on these matters was thrown by several recent Presidential lectures, as illustrated by the following extracts.

At the last General Assembly, in Honolulu in August 1995, Robin Muench considered the trade-offs between a tight disciplinary focus and a broader and more interdisciplinary approach. He noted that "The success of the present IAPSO assembly suggests the scientific community prefers the more disciplinary approach... this preference is not limited to IAPSO... we are deluged with a vast published literature containing far less really significant new information per printed page than in the past. It would be virtually impossible today for a scientists to remain highly conversant in all aspects of physical oceanography... investigators have become increasingly focused on specific subareas or topics... it is very difficult to arrive at a "great discovery" in the field of oceanography today... We are witnessing a shift away from discovery science toward focused science."

On the other hand, he was aware of the need to justify research to the government entities that fund most of it:

"If this specialized research can be tied in through a simple conceptual model to a climate cycle that might influence agriculture, then the official is likely both to understand and to be sympathetic... conceptual ties between physical processes and fisheries processes lead naturally to the topic of economic impact of fisheries fluctuations. We understand amazingly little about such coupled physical-biological phenomena. Convincing arguments made by the scientific community, using examples which are visible to nonscientific officials and the general public, can go a long way toward insuring the future health of oceanography."

In a different approach, twelve years earlier, at the General Assembly in Hamburg, Devendra Lal had touched on the question of cooperation among scientists of different disciplines, and on the climate forcing of this enhanced interaction:

"The ocean, just a tub of water: yet so difficult to understand! The pleasure lies in seeking its structure and learning how it regulates its physicochemical and biological processes in its gigantic setting within the planet earth. The ocean exhibits a wide range of characteristic space and time scales ...So far the biologist, for example, could not bother himself much with what the physicist or the geophysicist were doing but now observations by these scientists have so closely meshed together that it is no longer possible to lead a highly specialized life.... There are front-ranking programs in oceanography in which international cooperation is in fact the key word: e.g., the newly emerging important area of climatological studies related to the oceans. This is by itself a large area of research requiring inputs from the astrophysicist, the physical oceanographer, the biologist, the geologist and others. This area was identified earlier as an important one, but has emerged as an active area of investigation only in this decade since we now understand the oceans better and since the present level of international cooperative efforts makes this study feasible."

The problem of interdisciplinary cooperation continues to underline the question of how best to organize to make it possible. Henry Charnock, as IUGG President in 1975, put it this way:

"The relations between the various ICSU bodies are complex; I like to conceive of the Unions as being the warp and the Scientific Committees the weft of an evolving tapestry. One can hardly claim that the weaving produces especially neat and regular patterns, but the product is certainly strong and flexible. We can play our part, in conjunction with governmental organizations, in ensuring that important problems are tackled in an imaginative way."

In his Presidential lecture at the 1979 General Assembly, after commenting on the limitations of organizations, Bob Stewart said "we should only use organizations to do those things that can only be done by organizations. And where they can be done without, let's do without them!" In discussing what organizations can and can't do, Stewart commented that "in many ways, the operating arm that IAPSO has used in 

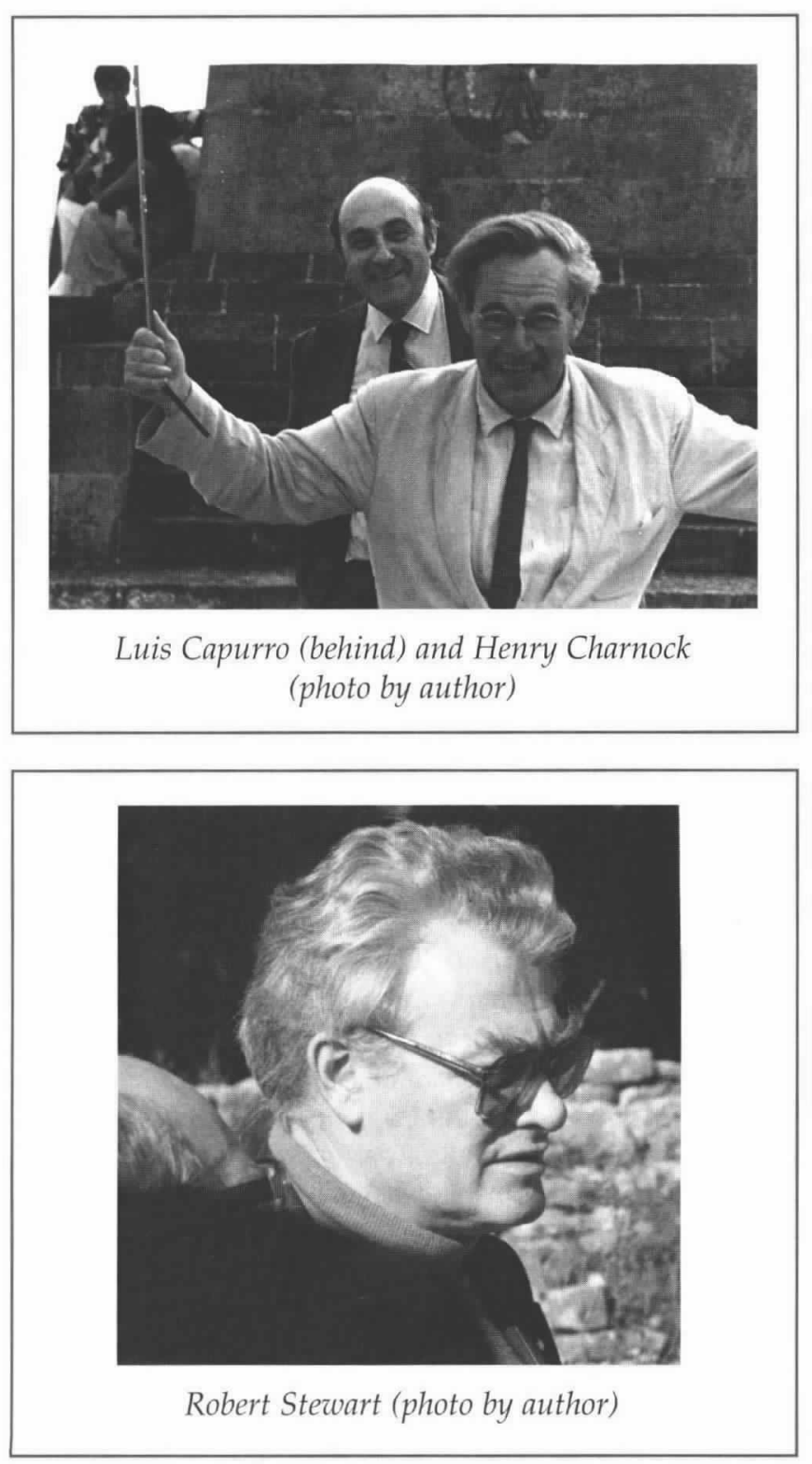

dealing with the world has been ...SCOR..SCOR can act in a way that we cannot, often because it has a bigger budget and they meet more often."

Stewart enlarged on the point of the advantage to working through bodies such as IAPSO and SCOR: "We should point out to the authorities who have money to dispense-however limited that may bethat if some portion of that money is used to support non-governmental bodies, it has enormous leverage and will bring resources into play at quite a different level and of quite a different magnitude than if the money is spent elsewhere, either internally in their own institute or through the United Nations bodies."

Stewart also discussed the 1967 debate on whether IAPSO should leave IUGG to join with biologists and others in an International Union of Marine Sciences.

"There was a great deal of debate at that time which I then described (and I have never seen any reason to change my mind) as being something like the internal debate of a man who was really very fond of his wife. But there was another very attractive woman around who was prepared to be his mistress. His difficulty was how to keep his wife and take the mistress as well...we in IAPSO at the Berne Assembly decided to try. If you take our wife as being IUGG with its meteorologists and its solid earth geophysicists, we decided to stay in the IUGG rather than break away. In taking the mistress, which is the biologist, we had it arranged that SCOR would change its character to be much more like a Union. It seems to have worked...We belong in these two camps."

Without daring to comment on this particular metaphor, all these thoughts, expressed in different ways through the years, have led me to some conclusions:

1. IAPSO and its scientific sessions continue to represent the cutting edge of research into the physical sciences of the ocean, but it also wrestles with the question of where it belongs in the structure of international marine science.

2. While emphasizing the physical aspects of marine science, IAPSO has from the start found opportunities to cooperate with biological oceanographers.

3. A move to institutionalize this cooperation with the 1970 proposal to create an International Union of Marine Sciences was rejected in favor of the looser coupling offered through participation, along with IABO and other associations, in the governance of SCOR.

4. IAPSO resolved the question of how best to influence the actions and priorities of the Intergovernmental Oceanographic Commission and other intergovernmental marine science organizations by choosing to act along with the other associations through SCOR.

It seems to me that the future of IAPSO is in no way clouded by these institutional issues that have tantalized it through the decades. Proof lies in the present Ocean Odyssey which provides ample evidence of the benefits of an interdisciplinary as well as an international science to deal with the broad and interwoven nature of the ocean. Ded

\section{Bibliographic Note}

This paper is based on the Bulletins of the Section of Physical Oceanography, International Union of Geodesy and Geophysics, Numbers 1-17 (1921-1931) and the Procés-Verbaux of IAPO/IAPSO, Numbers 1-17 (1934-1988), subsequently IAPSO Proceedings 18 (1993) and 19 (1995). See also: Went, A.E.J., 1972: Seventy Years Agrowing. A history of the International Council for the Exploration of the Sea 1902-1972. Rapp. P.v. Réun. Cons. Int. Explor. Mer, 165, 252 pp. 